\title{
Effectiveness of physical therapy for pregnancy-related low back and/or pelvic pain after delivery: A systematic review
}

\author{
Caroline Wanderley Souto Ferreira, $\mathrm{PhD}^{1}$ and Francisco Alburquerque-Sendín, $\mathrm{PhD}^{2}$ \\ ${ }^{1}$ Physiotherapy Department, Universidade Federal de Pernambuco, Recife, PE, Brazil \\ ${ }^{2}$ Área de Fisioterapia, Universidad de Salamanca, Salamanca, Castilla y León, Spain
}

\begin{abstract}
The aim of this work was to investigate the effectiveness of physical therapy for the treatment of low back pain (LBP) and pelvic girdle pain (PGP) related to pregnancy after delivery. A systematic review of studies published since 1985 in the databases Medline, PEDro, SciELO, SCOPUS, LILACS, and the Cochrane Library was made. Studies that focused on postpartum LBP or PGP, without being related to pregnancy or in other non-pregnant patients, were excluded, as were papers addressing LBP or PGP indicating radiculopathy, rheumatism, or any other serious disease or pathologic condition. In accordance with the exclusion criteria and duplicate articles, of the 105 articles retrieved only six were considered for quality assessment with the PEDro Scale. Among these six papers, two were follow-ups, such that only four trials were included in this review. All trials used exercise for motor control and stability of the lumbopelvic region, but with different intervention approaches. The study affording the best evidence used individual guidance and adjustments given by the physiotherapists. Nevertheless, this systematic review was inconclusive and showed that more randomized clinical trials, with good quality, are needed.
\end{abstract}

\section{INTRODUCTION}

Pregnancy is an event that leads to important changes in women's bodies (Rodacki, Fowler, Rodacki, and Birch, 2002). Furthermore, some changes have been reported to underlie the etiology of low back pain (LBP) and pelvic girdle pain (PGP; Kristiansson, Svardsudd, and von Schoultz, 1996; Mens et al, 1996; Norén, Ostgaard, Johansson, and Ostgaard, 2002). Although mechanical and hormonal factors for the occurrence of back pain in pregnancy are well known, there is limited information regarding the course of back pain after pregnancy (Turgut, Turgut, and Çetinsahin, 1998).

After delivery, the complaints usually disappear within a period of 6 months. However, in a small

Accepted for publication 19 October 2012

Address correspondence to Caroline Wanderley Souto Ferreira, Departamento de Fisioterapia, Universidade Federal de Pernambuco, Av. Prof. Moraes Rego, 1235 Cidade Universitária, Recife, PE, CEP 50670-901, Brazil E-mail: caroline.wanderley@ufpe.br percentage of patients complaints about pain persist and symptoms may last for years. The prevalence for PGP and/or LBP after delivery ranges from $5 \%$ to 37\% (Ronchetti, Vleeming, and Wingerden, 2008).

In most of the work described in the literature, no distinction is made between LBP and PGP (Ostgaard, Zetherstrom, and Roos-Hansson, 1997; Ostgaard, Zetherstrom, Roos-Hansson, and Svanberg, 1994). In fact, it has been concluded that PGP is a specific form of LBP that can occur separately or concurrently with LBP (Vleeming et al, 2008). This pain can have an adverse impact on the quality of life (QOL) and on ordinary daily activities such as load-bearing, cleaning, sitting, and walking abilities of the women affected, and there is some evidence of socioeconomic detriment, mainly as a consequence of job absenteeism (Norén, Ostgaard, Nielsen, and Ostgaard, 1997; Pennick and Young, 2007; Sydsjo, Sydsjo, and Wijma, 1998).

Taking the above reasons into account, the aim of the present systematic review was to investigate the effectiveness of physiotherapy for the treatment of pregnancy-related LBP and PGP after delivery. 


\section{METHODS}

\section{Literature search}

Literature searches were conducted using PubMed, Medline, SciELO, LILACS, Cochrane Collaboration Database, SCIRUS, Scopus, and Physiotherapy Evidence Database (PEDro). Two searches were performed and the key words used in both were obtained from the Medical Subject Headings $(\mathrm{MeSH})$. In the first search, the combination of the following key words was used: "low back pain" and "physiotherapy" and "postpartum period." For the second one, the terms "low back pain" and "physiotherapy" and "pregnancy" were used. The corresponding terms in Portuguese (lombalgia and fisioterapia and puerpério or pós-parto; lombalgia and fisioterapia and gravidez) and Spanish ("dolor de la región lumbar" and fisioterapia and puerperio or postpartum; "dolor de la región lumbar" and fisioterapia and embarazo) were used for the searches in Medline and LILACS.

\section{Inclusion and exclusion criteria}

In the present systematic review, only randomized clinical trials (RCTs) were used. Furthermore, only the RCTs published from January 1985 to December 2010 were included. This was due to an increase in back pain research after 1985, in agreement with Cherkin (1998). The inclusion and exclusion criteria used here are described in Table 1. Using these inclusion and exclusion criteria, the citations retrieved from each database were filtered once and then again by reading the title and abstract, respectively. Only if it could be clearly determined from the title and abstract that a given study did not meet the criteria was that study excluded. All other studies were obtained in their full text to determine the appropriateness for inclusion in this systematic review.

\section{Quality assessment}

The trials were rated using the PEDro criteria (Bhogal, Teasell, Foley, and Speechley, 2005). According to Olivo et al (2008), the PEDro Scale appears to be the most useful tool to assess the methodological quality of physiotherapy trials. It consists of 10 quality ratings, each receiving either a yes or no score, as follows: 1) subjects were randomly allocated to groups; 2) allocation was concealed; 3 ) similarity of the groups; 4, 5, 6) all participants and all those who administered the therapy and the assessors were blind as to the nature of the study; 7) adequacy of
TABLE 1 Inclusion and exclusion criteria.

\begin{tabular}{|c|c|}
\hline Inclusion criteria & Exclusion criteria \\
\hline $\begin{array}{l}\text { Randomized controlled trials } \\
\text { (RCTs) }\end{array}$ & $\begin{array}{l}\text { Studies that focus on post- } \\
\text { partum LBP or PGP with } \\
\text { no relationship to the } \\
\text { previous pregnancy or in } \\
\text { other non-pregnant } \\
\text { patients }\end{array}$ \\
\hline $\begin{array}{l}\text { The study had to address } \\
\text { patients who had LBP and/or } \\
\text { PGP during their pregnancy } \\
\text { or pregnancy-related after } \\
\text { delivery }\end{array}$ & $\begin{array}{l}\text { LBP or PGP indicating } \\
\text { radiculopathy, } \\
\text { rheumatism, or other } \\
\text { serious disease or } \\
\text { pathologic condition }\end{array}$ \\
\hline \multicolumn{2}{|l|}{ Papers written in any language } \\
\hline \multicolumn{2}{|l|}{ RCT published since 1985} \\
\hline $\begin{array}{l}\text { The study had to use at least } \\
\text { one outcome measure to } \\
\text { determine the effect of the } \\
\text { physiotherapy (e.g., pain } \\
\text { intensity, quality of life, } \\
\text { restriction in daily life } \\
\text { activities) }\end{array}$ & \\
\hline $\begin{array}{l}\text { It had to have been published in } \\
\text { a peer-reviewed journal }\end{array}$ & \\
\hline
\end{tabular}

follow-up; 8) analyzed by intention to treat; 9) statistical comparisons between groups; 10) measures of variability. The closer the score was to 10 , the better the quality of the study.

\section{Data acquisition}

After careful selection using the PEDro Scale, data were acquired by the authors on a data extraction form (i.e., description of study, sample, intervention protocol, primary and secondary outcomes, etc). One of the authors (CWSF) obtained the data initially and the second author (FAS) checked and edited all entries for accuracy and consistency. In case of disagreement, consensus was reached by discussion between the authors.

\section{RESULTS}

\section{Study selection and quality assessment}

A total of 105 articles were retrieved using the search strategy detailed in the Methods Section. Among them, only six were evaluated with the PEDro Scale (Table 2) and two out of six were follow-up studies.

The studies of Bastiaenen et al (2006), Bastiaenen et al (2008), and Mens, Snijders, and Stam (2000) had a score of 8 on the PEDro Scale, while the study 
TABLE 2 Quality assessment of the papers according to the PEDro scale.

\begin{tabular}{|c|c|c|c|c|c|c|c|c|c|c|c|}
\hline Author (year) & 1 & 2 & 3 & 4 & 5 & 6 & 7 & 8 & 9 & 10 & Total score \\
\hline Bastiaenen et al (2006) & $\mathrm{Y}$ & $\mathrm{Y}$ & $\mathrm{Y}$ & $\mathrm{N}$ & $\mathrm{N}$ & $\mathrm{Y}$ & $\mathrm{Y}$ & $\mathrm{Y}$ & $\mathrm{Y}$ & $\mathrm{Y}$ & 8 \\
\hline Bastiaenen et al (2008) & $\mathrm{Y}$ & $\mathrm{Y}$ & $\mathrm{Y}$ & $\mathrm{N}$ & $\mathrm{N}$ & $\mathrm{Y}$ & $\mathrm{Y}$ & $\mathrm{Y}$ & $\mathrm{Y}$ & $\mathrm{Y}$ & 8 \\
\hline Gutke, Sjodahl, and Oberg (2010) & $\mathrm{Y}$ & $\mathrm{Y}$ & $\mathrm{Y}$ & $\mathrm{N}$ & $\mathrm{N}$ & $\mathrm{Y}$ & $\mathrm{N}$ & $\mathrm{N}$ & $\mathrm{Y}$ & $\mathrm{Y}$ & 6 \\
\hline Mens, Snijders, and Stam (2000) & $\mathrm{Y}$ & $\mathrm{Y}$ & $\mathrm{Y}$ & $\mathrm{N}$ & $\mathrm{N}$ & $\mathrm{Y}$ & $\mathrm{Y}$ & $\mathrm{Y}$ & $\mathrm{Y}$ & $\mathrm{Y}$ & 8 \\
\hline Stuge, Laerum, Kirkesola, and Vollestad (2004) & $\mathrm{Y}$ & $\mathrm{Y}$ & $\mathrm{Y}$ & $\mathrm{N}$ & $\mathrm{N}$ & $\mathrm{Y}$ & $\mathrm{Y}$ & $\mathrm{N}$ & $\mathrm{Y}$ & $\mathrm{Y}$ & 7 \\
\hline Stuge, Veierod, Laerum, and Vollestad (2004) & $\mathrm{Y}$ & $\mathrm{Y}$ & $\mathrm{Y}$ & $\mathrm{N}$ & $\mathrm{N}$ & $\mathrm{N}$ & $\mathrm{N}$ & $\mathrm{N}$ & $\mathrm{Y}$ & $\mathrm{Y}$ & 5 \\
\hline
\end{tabular}

$1=$ subjects were randomly allocated to groups; $2=$ allocation was concealed; $3=$ similarity of the groups; 4, 5, $6=$ the participants, all those who administered the therapy and the assessors were blind as to the purposes of the study; $7=$ adequacy of follow-up; $8=$ analyzed by intention to treat; $9=$ statistical comparisons between groups; $10=$ measures of variability; $\mathrm{Y}=$ yes; $\mathrm{N}=$ no.

of Stuge, Laerum, Kirkesola, and Vollestad (2004) had a score of 7 , the study of Gutke, Sjödahl, and Oberg (2010) a score of 6 , and the study of Stuge, Veierod, Laerum, and Vollestad (2004) a score of 5.
These results suggest that the studies included have a low risk of bias (Balshem et al, 2011; Olivo et al, 2008). The flowchart of the review is shown in Figure 1.

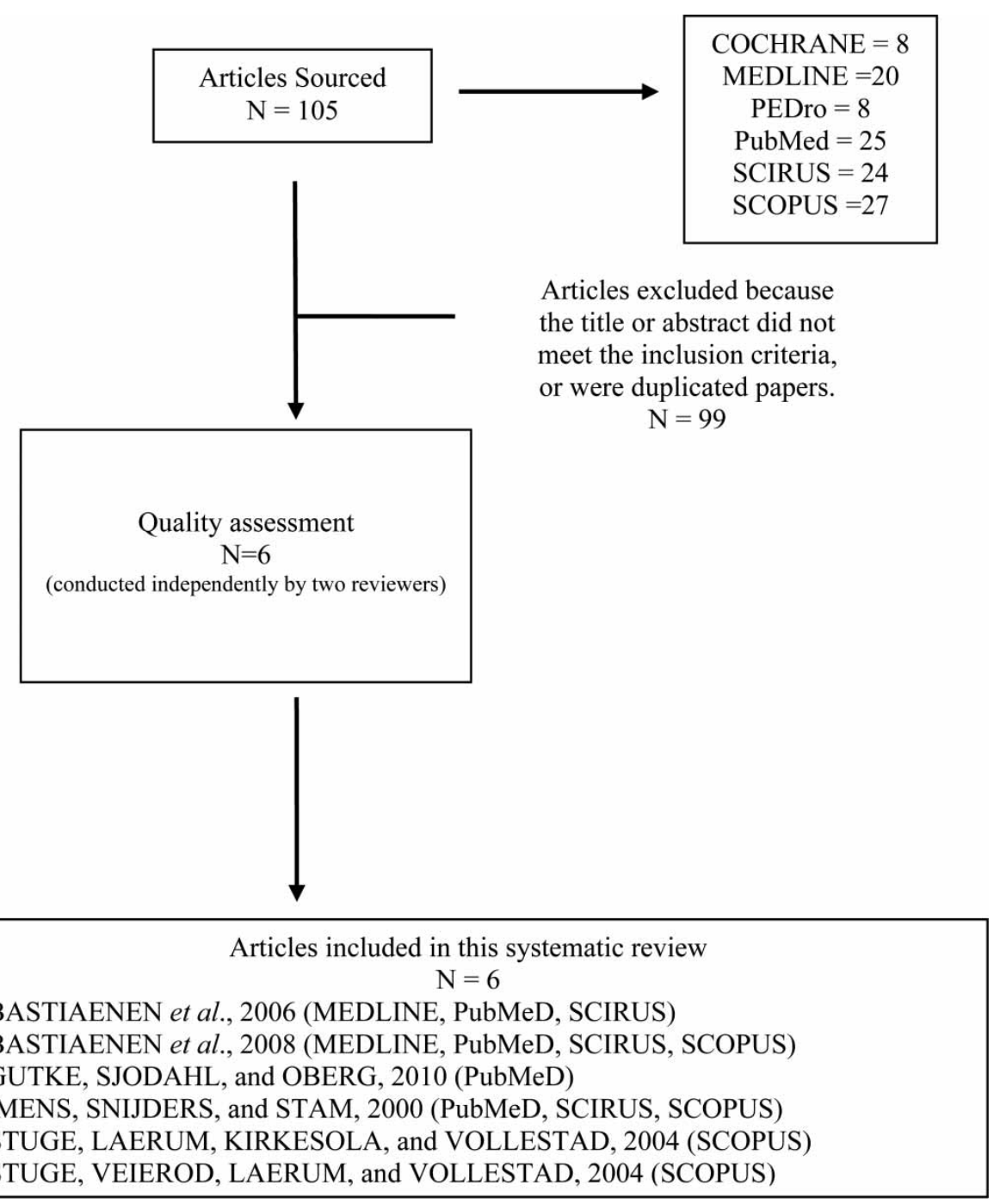

FIGURE 1 Review flow chart. 


\section{Study characteristics}

The characteristics of the studies can be seen in Tables 3 and 4. It is important to note that in the studies of Bastiaenen et al (2006 and 2008) the authors used the same sample from only one trial. However, the results were published separately. The first one (Bastiaenen et al, 2006) addressed the short-term results and the second one (Bastiaenen et al, 2008) was about long-term effectiveness and costs.

The studies of Stuge, Laerum, Kirkesola, and Vollestad (2004) and Stuge, Veierod, Laerum, and Vollestad (2004) are the same trial. The first study showed the results after intervention and at 1-year post-partum, and the second one reported a 2-year follow-up. In order to be more precise, here each study of Bastiaenen et al (2006 and 2008) and Stuge, Laerum, Kirkesola, and Vollestad (2004) and Stuge, Veierod, Laerum, and Vollestad (2004) will be addressed separately in the results.

Among the four trials, two were conducted in the Netherlands (Bastiaenen et al, 2006; Bastiaenen et al, 2008; Mens, Snijders, and Stam, 2000), one was carried out in Norway (Stuge, Laerum, Kirkesola, and Vollestad, 2004; Stuge, Veierod, Laerum, and Vollestad, 2004), and one in Sweden (Gutke, Sjodahl, and Oberg, 2010). All studies involved women in the post-partum period who were suffering from LBP and/or PGP, whose onset occurred during pregnancy or just after delivery.

The program in Bastiaenen's study was based on brief self-management and fear-avoidance techniques, but both groups received stabilizing exercises by a trained physiotherapist, except for some subjects in the control group, who chose to do nothing (34 out of 64 women). The other three trials were based on exercise, with a treatment program focusing on specific stabilizing exercises for PGP. However, the study of Mens, Snijders, and Stam (2000) used a videotape to teach the procedures to the patients. The clinical trial of Gutke, Sjodahl, and Oberg (2010) used a home-training concept with individual guidance and adjustment of the exercise program every second week by the physiotherapist, while only in the training program of Stuge, Laerum, Kirkesola, and Vollestad (2004) and Stuge, Veierod, Laerum, and Vollestad (2004) the patients were treated by a physiotherapist during all treatments (Tables 3 and 4). The follow-up time in the three studies ranged from 1 week after completion of the intervention period to 2 years after delivery. In all studies, pain was assessed as a primary or secondary outcome. The others measures are shown in Table 3.

\section{Participants}

A total of 341 subjects were included in this review, with a mean age and standard deviation of $31.6 \mathrm{SD}$ 3.6 years. All of them had at least one control group (CG), and the relationship between the number of subjects in the experimental group (EG) and the CG was equivalent, except for the trial of Gutke, Sjodahl, and Oberg (2010), which was composed of 32 subjects for the EG and 54 for the CG. There were no significant differences in any of the baseline statuses between the EG and CG, except for the age of participants and weight of the newborn babies in the trial of Gutke, Sjodahl, and Oberg (2010). Both groups were very similar in prognostic variables and in the baseline values of outcome measures (Table 3).

The Gutke, Sjodahl, and Oberg (2010) sample included 88 women, but had attrition and only 65 $(74 \%)$ and $60(68 \%)$ women completed the 3- and 6-month follow-up, respectively.

The Mens, Snijders, and Stam (2000) study suffered from methodological problems such as low statistical power caused by the limited number of subjects involved. Only 44 subjects were included and only $25 \%$ of the subjects in the training program terminated the exercise program, the others withdrawing because of increased pain. Additionally, four subjects (two from the EG and two from the CG) refused to participate in the second examination because of exacerbated symptoms after the first; for these subjects, the results were based only on the primary outcome measurements.

In the 2-year follow-up of Stuge, Veierod, Laerum, and Vollestad (2004), all 81 women returned the questionnaires; however, 16 were excluded from the analysis, mainly due to new pregnancies (Table 3).

\section{Adverse effects}

In their RCT, Mens, Snijders, and Stam (2000) reported that $25 \%$ of the subjects terminated their exercise program because of increased pain. Stuge, Laerum, Kirkesola, and Vollestad (2004), Stuge, Veierod, Laerum, and Vollestad (2004), and Gutke, Sjodahl, and Oberg (2010) did not find any increase in pain in their groups.

\section{Effectiveness of physiotherapy interventions}

The study of Bastiaenen et al (2006 and 2008) found that measurement at 12 weeks after delivery revealed a consistent difference in favor of the experimental 
TABLE 3 Study characteristics.

\begin{tabular}{|c|c|c|c|c|}
\hline Author/year & Sample & Intervention & Primary outcome measures/tool & Secondary outcome measures/tool \\
\hline $\begin{array}{l}\text { Bastiaenen et al } \\
\quad(2006)\end{array}$ & $\begin{array}{l}128 \text { subjects; } 62 \text { EG ( } 31.4 \\
\text { SD } 3.6 \text { years); } 64 \mathrm{CG} \\
\text { (31.5 SD } 3.1 \text { years) }\end{array}$ & $\begin{array}{l}\text { Brief self-management and fear-avoidance } \\
\text { techniques. Specific stabilizing exercises. } \\
\text { Free to choose usual care treatment by a } \\
\text { physiotherapist or do nothing }\end{array}$ & $\begin{array}{l}\text { Limitations in activities/RDQ; } \mathrm{MC}^{* /} \\
\text { VAS; GPE/7-point scale }\end{array}$ & $\begin{array}{l}\text { Pain today/VAS; Pain last week/VAS; IPA }{ }^{\dagger} \text {; } \\
\text { Fear of movement/TSK }{ }^{\ddagger} \text {; Health status/ } \\
\text { SF-36 }\end{array}$ \\
\hline $\begin{array}{l}\text { Bastiaenen et al } \\
\text { (2008) }\end{array}$ & $\begin{array}{l}\text { The same as Bastiaenen } \\
\text { et al (2006) }\end{array}$ & The same as Bastiaenen et al (2006) & The same as Bastiaenen et al (2006) & $\begin{array}{l}\text { The same as Bastiaenen et al (2006) plus } \\
\text { Cost-diary }\end{array}$ \\
\hline $\begin{array}{l}\text { Gutke, Sjodahl, } \\
\text { and Oberg } \\
(2010)\end{array}$ & 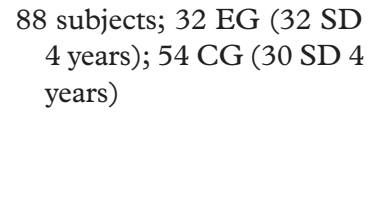 & $\begin{array}{l}\text { Home training of specific stabilizing } \\
\text { exercises targeting the local trunk } \\
\text { muscles. The women received } \\
\text { information about PGP and combined } \\
\text { pain }\end{array}$ & Disability/ODI & $\begin{array}{l}\text { Current pain intensity/VAS; pain intensity } \\
\text { previous week/VAS; pain frequency; EQ/ } \\
\text { 5D; EQ/VAS; wellbeing/VAS; symptom } \\
\text { satisfaction; Muscle function: activity of } \\
\text { the pelvic floor muscle; gait; hip extensors; } \\
\text { back flexors; back extensors }\end{array}$ \\
\hline $\begin{array}{l}\text { Mens, Snijders, } \\
\text { and Stam } \\
(2000)\end{array}$ & $\begin{array}{l}44 \text { subjects; } 16 \text { EG }(30.7 \\
\text { SD } 3.7 \text { years); } 14 \text { CG1 } \\
\text { (32.3 SD } 3.3 \text { years); } 14 \\
\text { CG2 (32.1 SD } 2.2 \text { years) }\end{array}$ & $\begin{array}{l}\text { Videotape giving the following instructions: } \\
\text { training of the diagonal trunk muscles. } \\
\text { training of the longitudinal trunk muscles. } \\
\text { Increase their daily living activities } \\
\text { without exercise }\end{array}$ & $\begin{array}{l}\text { Global impression of improvement } \\
\text { /Likert scale; pain (morning and } \\
\text { evening)/VAS; fatigue (morning and } \\
\text { evening)/VAS; aspects of perceived } \\
\text { health, NHP }\end{array}$ & $\begin{array}{l}\text { Gluteal pain provoked/PPPP test; mobility of } \\
\text { the pubic symphysis/X ray }\end{array}$ \\
\hline $\begin{array}{l}\text { Stuge, Laerum, } \\
\text { Kirkesola, and } \\
\text { Vollestad } \\
(2004)\end{array}$ & $\begin{array}{l}81 \text { subjects; } 78 \text { subjects ( } 1 \\
\text { year after delivery); } 40 \\
\text { EG ( } 32.4 \text { SD } 4.0 \text { years); } \\
41 \text { CG ( } 32.3 \text { SD } 3.8 \\
\text { years) }\end{array}$ & $\begin{array}{l}\text { Specific stabilizing exercises; without } \\
\text { specific stabilizing exercises }\end{array}$ & $\begin{array}{l}\text { Pain (morning and evening)/VAS; } \\
\text { functional status/Oswestry LBP } \\
\text { Disability Questionnaire }\end{array}$ & $\begin{array}{l}\text { Health status/SF-36; strength of adduction } \\
\text { and abduction of the hips/dynamometer } \\
\text { back muscle endurance/Sorensen test"; } \\
\text { disease severity/ASLR }\end{array}$ \\
\hline $\begin{array}{l}\text { Stuge, Veierod, } \\
\text { Laerum, and } \\
\text { Vollestad } \\
(2004)\end{array}$ & $\begin{array}{l}65 \text { subjects; } 34 \text { EG ( } 33.0 \\
\text { SD } 3.7 \text { years); } 31 \mathrm{CG} \\
\text { (33.1 SD } 3.8 \text { years) }\end{array}$ & $\begin{array}{l}\text { The same as Stuge, Laerum, Kirkesola, } \\
\text { and Vollestad (2004) }\end{array}$ & $\begin{array}{l}\text { Pain (morning and evening)/VAS; } \\
\text { functional status/Oswestry LBP } \\
\text { Disability Questionnaire }\end{array}$ & Health status/SF-36 \\
\hline \multicolumn{5}{|c|}{$\begin{array}{l}\text { MC = main complaint, EG = experimental group, CG = control group, RDQ = Roland Disability Questionnaire, VAS = Visual Analog rating Scale, GPE = global perceived } \\
\text { effect, IPA = impact on participation and autonomy, TSK = Tamp Scale for kinesiophobia, SF-36 = Short-Form-36, ODI = Oswestry Disability Index, EQ = EuroQol instrument, } \\
\text { NHP = Nottingham Health Profile, PPPP test = Posterior Pelvic Pain Provocation test, X ray = radiographic examination, LBP = lower back pain, ASLR = active straight leg rise. } \\
{ }^{*} \text { First main complaint was selected. } \\
{ }^{\dagger} \text { The sub-domains used were IPA self-care and appearance, IPA mobility and leisure, IPA social relationships, and IPA family role. } \\
\text { }{ }^{\ddagger} \text { The TSK total and the TSK fear-avoidance and TSK harm subscales were used. } \\
\text { \$The six major domains were used: NHP energy, NHP pain, NHP emotional reactions, NHP sleep, NHP social isolation, and NHP physical mobility. } \\
\text { "Assessed only } 1 \text { week after intervention. }\end{array}$} \\
\hline
\end{tabular}




\begin{tabular}{lll}
\hline Author/year & \multicolumn{1}{c}{ Period of the intervention } & Follow-up \\
\hline $\begin{array}{c}\text { Bastiaenen et al } \\
(2006)^{\dagger}\end{array}$ & $\begin{array}{c}\text { For the EG, an individualized self- } \\
\text { management approach of } 7-9 \text { sessions } \\
\text { for 30 minutes in a period of time of }\end{array}$ & 3 months after randomization \\
$\begin{array}{l}\text { 12 weeks was provided } \\
\text { Bastiaenen et al } \\
(2008)^{\dagger}\end{array}$ & $\begin{array}{l}\text { For the EG, an individualized self- } \\
\text { management approach of 7-9 sessions } \\
\text { for 30 minutes over 12 weeks was } \\
\text { provided }\end{array}$ & $\begin{array}{c}\text { months after randomization, } 6 \\
\text { months and 1 year after delivery }\end{array}$
\end{tabular}

Results (primary outcome)*

Results (secondary outcome)*

Gutke, Sjodahl, and EG was instructed to exercise $\geq 2$ times 3 and 6 months after inclusion Oberg (2010) per day and to perform each exercise with 10 repetitions and the CG had a single telephone contact with a

physiotherapist

\section{$\mathrm{RDQ}=-2.0\{-4.0 ; 0.0\} 0.05$; \\ subgroup $R D Q \geq 13^{\ddagger} ; \mathrm{RDQ}=$ \\ $-4.3\{-7.0 ;-1.5\} 0.003$}

$\mathrm{RDQ}=-1.6\{-2.9 ;-0.5\} 0.005$; subgroup $R D Q<13$; TSK (total)

$=-1,9\{-3.6 ;-0.15\} 0.03$; TSK activity avoidance $^{\mathbb{f}}=-1.3\{-2.3$; -0.3 ) 0.02; subgroup $R D Q \geq 13^{\ddagger}$; $\mathrm{RDQ}=-1.8\{-3.4:-0.14\} 0.03$; IPA self-care $=-1.7\{-3.0 ;-0.4\}$ 0.01 ; TSK activity avoidance ${ }^{\mathrm{I}}=$ $-1.5\{-2.7 ;-0.3\} 0.01$

ODI between the 2 groups: 3 -month follow-up ( $p=0.205)$; 6-month follow-up $(p=0.358)$
IPA self-care ${ }^{\S}=-1.0\{-1.9 ;-0.03\}$ $0.04 ;$ TSK total $=-2.4\{-3.8 ;-1.1\}$ 0.00 ; TSK fear avoidance ${ }^{\|}=-1.7$ $-2.6 ;-0.8\} 0.00$

3-month follow-up: pain frequency: $p=0.011$ in favor of treatment group Pain intensity: $p<0.001$ in favor of CG and EG in comparison with their baselines

Symptom satisfaction: $p=0.039$ in favor of EG in comparison with baseline value

Hip extension left leg: $p=0.047$ in favor of EG

Back extensor endurance and gait speed: $p<0.001$ in favor of contro group in comparison with baseline values

Gait speed: $p<0.05$ in favor of EG in comparison with baseline

Mean hip extension right leg: $p<0.05$ in favor of EG and CG in comparison with baseline values

Peak hip extension right leg: $p<0.05$ in favor of EG and in comparison with baseline values.

Mean hip extension left leg: $p<0.05$ in favor of EG and in comparison with its baseline and $p<0.05$ in favor of EG in comparison with the $\mathrm{CG}$ 6-month follow-up

Pain frequency: $p=0.022$ in favor of CG in comparison with baseline values Pain intensity: $p<0.001$ in favor of $\mathrm{CG}$ and $\mathrm{EG}$ in comparison with 
Mens, Snijders, and Stam (2000) II

Stuge, Laerum, Kirkesola, and Vollestad $(2004)^{* *}$
Videotape 1 (EG) gave instructions for heavy exercises, to be performed 3 times a week (Monday, Wednesday, and Friday), and instructions for light exercises, to be performed 3 times a day over 8 weeks

EG women were required to exercise for Within 1 week after the

30-60 minutes, 3 days a week and the CG received treatment approximately every second week. All patients were treated by experienced

physiotherapists over a period of 20 weeks baseline values Symptom satisfaction:

$p=0.001$ in favor of EG in

comparison with its baseline;

$p=0.022$ in favor of EG in

comparison with baseline values

Back extensor endurance: $p<0.05$ in favor of CG and EG in comparison

with baseline values

Gait speed: $p<0.05$ in favor of EG in comparison with baseline values

Mean hip extension right leg: $p<0.05$ in favor of EG and CG in comparison with baseline values

Peak hip extension right leg: $p<0.05$ in favor of CG in comparison with

baseline values

Mean hip extension left leg: $p<0.05$ in favor of EG in comparison with

baseline values

Peak hip extension left leg: $p<0.05$ in favor of EG in comparison with

baseline values

PPPP test $=$ on the right side, the EG scored better than the CG $p<0.05$ hospital was planned to occu

in 8 wame day of

the week and at the same time

intervention period and 1 year

after delivery. The test procedure was performed at approximately the same time of the day for each subject
One week after intervention all outcomes, except the SF-36 Role Emotional and SF-36 Mental

Health, were significant for the EG.

For the VAS, morning pain

$(p=0.001)$, evening pain

$(p<0.001)$. For the ODI

$(p<0.001)$. For the strength

abduction $(p=0.02)$ and for the

others, $p \leq 0.01$.

One year after delivery only the outcome SF-36 Mental Health was not significant, and the SF-36

Vitality, Social Functioning and

Role Emotional had a $p<0.05$,

while the others had a $p<0.01$. For

the VAS, morning pain

$(p<0.001)$, evening pain

$(p<0.001)$. For the ODI

$(p<0.001)$. 
TABLE 4 Continued

\begin{tabular}{|c|c|c|c|c|}
\hline Author/year & Period of the intervention & Follow-up & Results (primary outcome)* & Results (secondary outcome)* \\
\hline $\begin{array}{l}\text { Stuge, Veierod, } \\
\text { Laerum, and } \\
\text { Vollestad (2004) }\end{array}$ & $\begin{array}{l}\text { EG women were required to exercise for } \\
30-60 \text { minutes, } 3 \text { days a week and the } \\
\text { CG received treatment approximately } \\
\text { every second week. All patients were } \\
\text { treated by experienced } \\
\text { physiotherapists over a period of } 20 \\
\text { weeks }\end{array}$ & 2 years after delivery & $\begin{array}{l}\text { All outcomes such as Pain, morning } \\
(p<0.005) \text { and evening } \\
(p<0.001) \text {, Functional status, } \\
\text { ODI }(p<0.001) \text {, and Health } \\
\text { status, persisted }\end{array}$ & \\
\hline
\end{tabular}

EG = Experimental Group, CG = Control Group, RDQ = Roland Disability Questionnaire, IPA = Impact on Participation and Autonomy, TSK = Tamp Scale for Kinesiophobia, SF-36 $=$ Short-Form-36, PPPP test $=$ Posterior Pelvic Pain Provocation test.

$*$ Only results with significant differences are shown.

${ }^{\dagger}$ Differences between groups and $95 \%$ CIs were calculated. Primary analysis was performed by means of analysis of an independent $t$-test (for continuous variables) and a chi-square

test (for categorical variables), shown by $\mathrm{p}$-values (statistical differences $p \leq 0.05$ ).

‡Women with severe limitations

IPA self-care and appearance, which is a subdomain of the IPA.

"Differences between measurements (at the beginning and at the end of the study) were analyzed using one-way analysis of variance. Categorical data were compared with the Kruskal-

Wallis test (statistical differences $p<0.05$ )

TSK subscale.

융 **Student's $t$-test was used for continuous variables; ASLR Mann-Whitney tests were used for discontinuous variables, and nominal background variables were compared with

Pearson's chi squared test (statistical differences $p<0.025$ ). 
intervention, but only the primary outcome "limitations in activities" measured with the Roland Disability Questionnaire (RDQ) reached statistical significance. The authors performed a subgroup analysis to explore a possible different intervention effect in the subgroups of women with severe limitations (RDQ $\geq 13$ ) to their activities at baseline. They found a statistically significant and clinically relevant difference of 4.3 points in favor of the experimental intervention in the $\mathrm{RDQ} \geq 13$ subgroup (Table 4). The estimated treatment assignment effect revealed a statistically significant effect on the RDQ for the experimental group as compared with usual care. However, there did not appear to be any clinically important difference in the advantage of the experimental intervention over time (1 year after delivery). These results of binary logistic regression with the Global Perceived Effect (GPE) dichotomy outcome variable did not uncover statistically significant differences between either group at 3, 6, and 12 months. Significant secondary estimated treatment assignment effects were demonstrated in the total score of the Tampa Scale of Kinesiophobia and the Activity Avoidance subscale and the Impact on Participation and Autonomy on the self-care subscale. The women in both groups reported a substantial reduction in pain, and Visual Analog Scale (VAS) pain today and last week, and in the year after delivery (Table 4), but there were no significant differences between either the main study groups or their subgroups.

In the study of Gutke, Sjodahl, and Oberg (2010), regarding primary outcome in disability, no significant differences between groups could be found at 3- or 6month follow-up. Within-group comparisons revealed some improvement in both groups in terms of disability, pain, satisfaction with the reduction in symptoms and muscle function as compared with the baseline, although the majority still experienced PGP (Tables 3 and 4).

In the study of Mens, Snijders, and Stam (2000), comparison of results at the end of the 8-week intervention revealed no differences for the primary outcome measures between the experimental group and both control groups (Tables 3 and 4). It can be said that global improvement in the experimental group was not $20 \%$ better than in the control groups, with a confidence level of $95 \%$ for control group 1 and with a confidence level of more than $99 \%$ for control group 2. Regarding changes in the posterior pelvic pain provocation test (PPPP) test scores on the right side, the experimental group scored better than the control groups $(p<0.05)$.

In the study of Stuge, Laerum, Kirkesola, and Vollestad (2004) the highest scores in terms of effect sizes were observed for the Oswestry Disability Questionnaire (ODQ), evening pain, and the SF-36 subscales of physical functioning, physical role, and body pain in favor of the EG. The changes primarily occurred during the intervention period, with only minor changes thereafter. Regarding functional status, $75 \%$ of the subjects in the EG scored lower than 25 on the ODQ after treatment, whereas only $25 \%$ in the CG scored lower than this $(p<0.001)$ (Tables 3 and 4). This large difference persisted or was even more marked at 1-year post-partum. The same trend was seen for morning and evening pain, with significant differences between the groups after intervention and at 1 -year post-partum $(p<0.001)$. For instance, the group difference in median values for evening pain after treatment was $30 \mathrm{~mm}$ on the VAS. Health-related QoL was significantly higher in the EG than in the CG, both after the end of treatment and at the 1year follow-up visit, except on the scales of emotional role after therapy, and vitality and mental health after 1 year (Table 4). The differences in scores between the groups were especially large for physical functioning, physical role, and body pain $(p<0.001)$. The results of the physical tests uncovered statistically significant differences between the groups in change score during the intervention period, in favor of the EG (Table 4).

Finally, in the study of Stuge, Veierod, Laerum, and Vollestad (2004) the benefits of the specific stabilizing exercise program, previously reported after 1 year, for Pain (morning and evening), Functional status and Health status persisted at the 2-year follow-up.

\section{DISCUSSION}

In the present review, all trials were considered to be of good quality, with a PEDro score of five or higher (Ho, Sole, and Munn, 2009; Kromer et al, 2009; Maher, 2000; Maher et al, 2003).

All trials in this review used a stabilizing exercise program in their treatment protocol, which mainly differed in the way it was performed. In this sense, the intervention reported by Stuge, Laerum, Kirkesola, and Vollestad (2004) and Stuge, Veierod, Laerum, and Vollestad (2004) included individual guidance and adjustments given by physiotherapists without losing focus on body awareness and ergonomics. Bastiaenen et al (2006 and 2008) and Gutke, Sjödahl, and Öberg (2010) designed a home-training concept guided by physiotherapists, and Mens, Snijders, and Stam (2000) used videotapes.

Stabilizing exercise programs are considered a logical approach to treat PGP, based on spine 
muscle stabilization (Bergmark, 1989). This can be explained in terms of the role of the local musculature (internal oblique, transversus abdominis, multifidus, diaphragm and pelvic floor muscles). The multifidus in co-contraction with the transversus abdominis could improve the stabilization of the lumbar segments (Hides, Richardson, and Jull, 1996) and pelvis (Richardson et al, 2002). Hodges and Moseley (2003) reported that deep local muscles create a fine adjustment for intervertebral movement to improve pelvic stabilization, and superficial general muscles guide the orientation of the spine Moseley, Hodges, and Gandevia, 2002). This sequential perspective was maintained in the study reported by Stuge, Laerum, Kirkesola, and Vollestad (2004).

Pain intensity was used as a clinical outcome for all studies included in this systematic review. The assessment of pain is a constant in musculoskeletal research, probably due to the relevance of pain as a critical outcome to establish clinical decisions and to recommend an intervention for this specific problem (Guayatt et al, 2011). Further, pain is commonly assessed with the same tools (i.e., VAS), which affords consistency to the reviews addressing this symptom. Pain decreased in the trials of Stuge, Laerum, Kirkesola, and Vollestad (2004), Stuge, Veierod, Laerum, and Vollestad (2004), and Bastiaenen et al (2006 and 2008). In contrast, $25 \%$ of the experimental group in the trial of Mens, Snijders, and Stam (2000) stopped training because of pain or fatigue. This negative outcome may be explained in terms of the way the intervention was performed, because those authors used videotapes, while in the trials of Stuge, Laerum, Kirkesola, and Vollestad (2004), Stuge, Veierod, Laerum, and Vollestad (2004) the patients were supervised regularly by a physiotherapist so that they would not injure themselves by performing the exercises inappropriately. Although a reduction in pain could be due to the natural course of the disorder, the support and counseling of the physiotherapist and the patient's understanding are relevant for the success of the interventions (Liddle, Baxter, and Gracey, 2004). This may also result in an increase in indirect adherence to the treatment, as reported in the study of Stuge, Laerum, Kirkesola, and Vollestad (2004), when participants of the experimental group reported accomplishing, on average, $80 \%$ of their exercise program.

When the period of intervention was taken into account, it was seen that Mens, Snijders, and Stam (2000), Stuge, Laerum, Kirkesola, and Vollestad (2004) and Stuge, Veierod, Laerum, and Vollestad (2004) followed the guidelines from the American College of Sports Medicine (2002) to increase strength and endurance in untrained individuals, since it has been shown that the majority of increases in strength takes place within the first 4-8 weeks (Kraemer et al, 2002). However, in this review it was seen that pain only decreased in the patients treated over a period of 20 weeks.

The studies of Stuge, Laerum, Kirkesola, and Vollestad (2004) and Stuge, Veierod, Laerum, and Vollestad (2004) and Bastiaenen et al (2006 and 2008) introduced a new method for treating pregnancyrelated PGP and/or LBP (i.e., the biopsychosocial approach). In this model, a person is seen as a system integrating biological, psychological, and social dimensions. This method differs from the biomedical model, which views disability as a problem of the individual, caused directly by the disease, which in turn requires medical care provided in the form of individual treatment by professionals (World Health Organization, 2001). In particular, the protocol of Stuge, Veierod, Laerum, and Vollestad (2004) is of interest since it is the only study showing a consistently strong positive effect at short term.

For an analysis of the quality of the evidence, based on the GRADE approach (Balshem et al, 2011; Furlan et al, 2009), pain as the only characteristic assessed in all studies, and all primary outcomes for each study (disability, main complaint, GPE/global impression of improvement, fatigue, and aspects of perceived health) were selected (Table 5). A high quality of evidence was found for pain. Disability, main complaint, GPE/global impression of improvement, fatigue, and aspects of perceived health showed very low-to-moderate quality results, casting doubt on the confidence of the estimated effects.

According to the analyses, this review shows the best evidence from the studies by Stuge, Laerum, Kirkesola, and Vollestad (2004) and Stuge, Veierod, Laerum, and Vollestad (2004), whose intervention was based on the principles from the biopsychosocial model and from the integrated model of function. The principles of the integrated model of function have four components - three physical: 1) form closure; 2) force closure; and 3) motor control and one psychological: emotions; and their implications for the lumbopelvic-hip region (Lee, 2007). However, taking into account the results of all studies, it can be seen that the biopsychosocial model approach was not effective in all cases, because only the primary outcome, limitations in activities, improved in the EG in the studies of Bastiaenen et al (2006 and 2008). One of the most important differences among the studies was the application protocol of the interventions, and hence we posit that the manner of performing the stabilizing exercises could influence the results. Individually adjusted and 
TABLE 5 Quality analysis (GRADE approach).

\begin{tabular}{|c|c|c|c|c|c|c|c|c|}
\hline $\begin{array}{l}\text { No. of } \\
\text { studies }\end{array}$ & Design & Limitations & Inconsistency & Indirectness & Imprecision & $\begin{array}{l}\text { Publication } \\
\text { bias }\end{array}$ & $\begin{array}{c}\text { Other } \\
\text { considerations }\end{array}$ & Quality \\
\hline \multicolumn{9}{|c|}{ Pain intensity (assessed by VAS) } \\
\hline 4 & $\begin{array}{l}\text { Randomized } \\
\text { trial }\end{array}$ & $\begin{array}{l}\text { No serious } \\
\text { limitations }\end{array}$ & $\begin{array}{l}\text { No serious } \\
\text { inconsistency }\end{array}$ & $\begin{array}{l}\text { No serious } \\
\text { indirectness }\end{array}$ & $\begin{array}{l}\text { No serious } \\
\text { imprecision }\end{array}$ & Undetected & None & $\oplus \oplus \oplus \oplus: \mathrm{HIGH}$ \\
\hline \multicolumn{9}{|c|}{ Disability (assessed by validated questionnaires) } \\
\hline 3 & $\begin{array}{l}\text { Randomized } \\
\text { trial }\end{array}$ & $\begin{array}{l}\text { No serious } \\
\text { limitations }\end{array}$ & Serious* & $\begin{array}{l}\text { No serious } \\
\text { indirectness }\end{array}$ & $\begin{array}{l}\text { No serious } \\
\text { imprecision }\end{array}$ & Undetected & None & $\begin{array}{l}\oplus \oplus \oplus \text { O: } \\
\quad \text { MODERATE }^{\dagger}\end{array}$ \\
\hline \multicolumn{9}{|c|}{ Main complaint (assessed by VAS) } \\
\hline 1 & $\begin{array}{l}\text { Randomized } \\
\text { trial }\end{array}$ & $\begin{array}{l}\text { No serious } \\
\text { limitations }\end{array}$ & Serious* & Serious ${ }^{\ddagger}$ & $\begin{array}{l}\text { No serious } \\
\text { imprecision }\end{array}$ & Undetected & None & $\oplus \oplus$ OO: LOW $^{\dagger}$ \\
\hline \multicolumn{9}{|c|}{ Global perceived effect/Global impression of improvement (assessed by 7-point scale and 3-point Likert scale) } \\
\hline 2 & $\begin{array}{l}\text { Randomized } \\
\text { trial }\end{array}$ & $\begin{array}{l}\text { No serious } \\
\text { limitations }\end{array}$ & Serious* & Serious ${ }^{\ddagger}$ & Serious $\$$ & Undetected & None & $\begin{array}{l}\oplus \text { OOO: VERY } \\
\text { LOW }^{\dagger}\end{array}$ \\
\hline \multicolumn{9}{|c|}{ Fatigue (assessed by VAS) } \\
\hline 1 & $\begin{array}{l}\text { Randomized } \\
\text { trial }\end{array}$ & $\begin{array}{l}\text { No serious } \\
\text { limitations }\end{array}$ & Serious* & $\begin{array}{l}\text { No serious } \\
\text { indirectness }\end{array}$ & $\begin{array}{l}\text { No serious } \\
\text { imprecision }\end{array}$ & Undetected & None & $\begin{array}{l}\oplus \oplus \oplus \text { O: } \\
\quad \text { MODERATE }^{\dagger}\end{array}$ \\
\hline \multicolumn{9}{|c|}{ Aspects of perceived health (assessed by the Nottingham Health Profile) } \\
\hline 1 & $\begin{array}{l}\text { Randomized } \\
\text { trial }\end{array}$ & $\begin{array}{l}\text { No serious } \\
\text { limitations }\end{array}$ & Serious* & $\begin{array}{l}\text { No serious } \\
\text { indirectness }\end{array}$ & $\begin{array}{l}\text { No serious } \\
\text { imprecision }\end{array}$ & Undetected & None & $\begin{array}{l}\oplus \oplus \oplus \text { O: } \\
\quad \text { MODERATE }^{\dagger}\end{array}$ \\
\hline
\end{tabular}

*The different studies used different assessment tools or an isolated study assessed this outcome, which condition the quality of the evidence for the review.

${ }^{\dagger}$ At least one study did not present this outcome and at least one quality domain was not present.

¥The complaints were selected by the women of the study and this tool could be inaccurate for other countries, cultures, etc.

${ }^{\S}$ The global perceived effect was dichotomized (Bastiaenen et al, 2006, 2008) and the 3-point scale did not afford any confidence interval. 
guided exercises supervised by physiotherapists afforded better results than exercises given as a video-tape or as home-based exercises for PGP.

In sum, and as the most important implication for practice, the review shows that individual guidance and adjusted exercises might be more recommendable for PGP, at least with respect to protocols with less or no contact.

This review had strengths, including no language limitation and the search through many relevant electronic databases. Nevertheless, its power is limited by the small number of studies found. Thus, as research implications, this review shows that there is an important lack of high-quality research in this field of knowledge.

There is weak evidence (exclusively from Stuge, Veierod, Laerum, and Vollestad (2004) study on pain symptom) concerning the effectiveness of physical therapy for pregnancy-related LBP and/or PGP after delivery.

\section{CONCLUSIONS}

This systematic review is inconclusive regarding the effectiveness of physical therapy for pregnancyrelated LBP and/or pelvic pain after delivery. There are few studies with good quality in this field. More randomized clinical trials on this topic, with high quality, are in need.

\section{Acknowledgments}

We thank Sonia Martin Castilla from the library of the Department of Physiotherapy of the University of Salamanca for her help and cooperation.

Declaration of Interest: The main funding for this study was provided by the Fundación Carolina in Spain. The authors report no conflicts of interest. The authors are responsible for the content and writing of the paper.

\section{REFERENCES}

Balshem H, Helfand M, Schünemann HJ, Oxman AD, Kunz R, Brozek J, Vist GE, Falck-Ytter Y, Meerpohl J, Norris S, Guyatt GH 2011 GRADE guidelines: 3. Rating the quality of evidence. Journal of Clinical Epidemiology 64: 401-406

Bastiaenen CH, Bie RA, Wolters PM, Vlaeyen JW, Leffers P, Stelma F, Bastiaanssen JM, Essed GG, Brandt PA 2006 Effectiveness of a tailor-made intervention for pregnancy-related pelvic girdle and/or low back pain after delivery: Short-term results of a randomized clinical trial. BMC Musculoskeletal Disorders 7: 19
Bastiaenen CH, Bie RA, Vlaeyen JW, Goossens, ME, Leffers P, Wolters PM, Bastiaanssen JM, Brandt PA, Essed GG 2008 Long-term effectiveness and costs of a brief self-management intervention in women with pregnancy-related low back pain after delivery. BMC Pregnancy Childbirth 8: 19

Bergmark A 1989 Stability of the lumbar spine. A study in mechanical engineering. Acta Orthopaedica Scandinavica Supplementum 230: 1-54

Bhogal SK, Teasell RW, Foley NC, Speechley MR 2005 The PEDro scale provides a more comprehensive measure of methodological quality than the Jadad Scale in stroke rehabilitation literature. Journal of Clinical Epidemiology 58: 668-673

Cherkin DC 1998 Primary care research on lower back pain: The state of the science. Spine 23: 1997-2002

Furlan AD, Pennick V, Bombardier C, van Tulder M; Editorial Board, Cochrane Back Review Group 20092009 updated method guidelines for systematic reviews in the Cochrane Back Review Group. Spine 34: 1929-1941

Guayatt GH, Oxman AD, Kunz R, Atkins D, Brozek J, Vist Gunn, Alderson P, Glasziou P, Falck-Ytter, Holger J, Schunemann HJ 2011 GRADE guidelines: 2. Framing the question and deciding on important outcomes. Journal of Clinical Epidemiology 64: 395-400

Gutke A, Sjödahl J, Oberg B 2010 Specific muscle stabilizing as home exercises for persistent pelvic girdle pain after pregnancy: A randomized, controlled clinical trial. Journal of Rehabilitation Medicine 42: 929-935

Hides JA, Richardson CA, Jull GA 1996 Multifidus muscle recovery is not automatic after resolution of acute, first-episode low back pain. Spine 21: 2763-2769

Ho CY, Sole G, Munn J 2009 The effectiveness of manual therapy in the management of musculoskeletal disorders of the shoulder: A systematic review. Manual Therapy 14: 463-474

Hodges PW, Moseley GL 2003 Pain and motor control of the lumbopelvic region: Effect and possible mechanisms. Journal of Electromyography and Kinesiology 13: 361-370

Kraemer WJ, Adams K, Cafarelli E, Dudley GA, Dooly C, Feigenbaum MS, Fleck SJ, Franklin B, Fry AC, Hoffman JR, Newton RU, Potteiger J, Stone MH, Ratamess NA, Triplett-McBride T, American College of Sports Medicine 2002 Progression models in resistance training for healthy adults. Medicine and Science in Sports and Exercise 34: 364-380

Kristiansson P, Svardsudd K, von Schoultz B 1996 Serum relaxin, symphyseal pain, and back pain during pregnancy. American Journal of Obstetrics and Gynecology 175: 1342-1347

Kromer TO, Tautenhahn UG, De Bie RA, Staal JB, Bastiaenen CH 2009 Effects of physiotherapy in patients with shoulder impingement syndrome: A systematic review of the literature. Journal of Rehabilitation Medicine 41: 870-880

Lee D 2007 The pelvic girdle: An approach to the examination and treatment of the lumbopelvic-hip region. In: Lee D (ed) Principles of the Integrated Model of Function and Its Application to the Lumbopelvic-hip Region, 3rd edn, pp 41-54. London, Churchill Livingstone

Liddle SD, Baxter GD, Gracey JH 2004 Exercise and chronic low back pain: What works? Pain 107: 176-190

Maher CG 2000 A systematic review of workplace interventions to prevent lower back pain. Australian Journal of Physiotherapy 46: 259-269

Maher CG, Sherrington C, Herbert RD, Moseley AM, Elkins M 2003 Reliability of the PEDro Scale for rating quality of randomized controlled trials. Physical Therapy 83: 713-721

Mens JM, Vleeming A, Stoeckart R, Stam HJ, Snijders CJ 1996 Understanding peripartum pelvic pain. Implications of a patient survey. Spine 21: 1363-1370 
Mens JM, Snijders CJ, Stam HJ 2000 Diagonal trunk muscle exercises in peripartum pelvic pain: A randomized clinical trial. Physical Therapy 80: 1164-1173

Moseley GL, Hodges PW, Gandevia SC 2002 Deep and superficial fibers of the lumbar multifidus muscle are differentially active during voluntary arm movements. Spine 27: E29-E36

Norén L, Ostgaard S, Nielsen TF, Ostgaard HC 1997 Reduction of sick leave for lumbar back and posterior pelvic pain in pregnancy. Spine 22: 2157-2160

Norén L, Ostgaard S, Johansson G, Ostgaard HC 2002 Lumbar back and posterior pelvic pain during pregnancy: A 3-year follow-up. European Spine Journal 11: 267-271

Olivo SA, Macedo LG, Gadotti IC, Fuentes J, Stanton T, Magee DJ 2008 Scales to assess the quality of randomized controlled trials: A systematic review. Physical Therapy 88: 156-175

Ostgaard HC, Zetherstrom G, Roos-Hansson E, Svanberg B 1994 Reduction of back and posterior pelvic pain in pregnancy. Spine 19: 894-900

Ostgaard HC, Zetherström G, Roos-Hansson E 1997 Back pain in relation to pregnancy: A 6-year follow-up. Spine 22: 2945-2950

Pennick VE, Young G 2007 Interventions for preventing and treating pelvic and back pain in pregnancy. Cochrane Database Systematic Reviews 18: CD001139

Richardson CA, Snijders CJ, Hides JA, Damen L, Pas MS, Storm J 2002 The relation between the transversus abdominis muscles, sacroiliac joint mechanics, and low back pain. Spine 27: 399-405
Rodacki CL, Fowler NE, Rodacki AL, Birch K 2002 Stature loss and recovery in pregnant women with and without lower back pain. Archives of Physical Medicine and Rehabilitation 84: 507-512

Ronchetti I, Vleeming A, Wingerden JP 2008 Physical characteristics of women with severe pelvic girdle pain after pregnancy. Spine 33: E145-E151

Stuge B, Laerum E, Kirkesola G, Vollestad N 2004 The efficacy of a treatment program focusing on specific stabilizing exercises for pelvic girdle pain after pregnancy: A randomized controlled trial. Spine 29: 351-359

Stuge B, Veierod MB, Laerum E, Vollestad N 2004 The efficacy of a treatment program focusing on specific stabilizing exercises for pelvic girdle pain after pregnancy: A two-year follow-up of a randomized clinical trial. Spine 29: E197-E203

Sydsjo A, Sydsjo G, Wijma B 1998 Increase in sick leave rates caused by back pain among pregnant Swedish women after amelioration of social benefits. A paradox. Spine 23: 1986-1990

Turgut F, Turgut M, Çetinsahin M 1998 A prospective study of persistent back pain after pregnancy. Obstetrics and Gynecology 80: 45-48

Vleeming A, Albert HB, Ostgaard HC, Sturesson B, Stuge B 2008 European guidelines for the diagnosis and treatment of pelvic girdle pain. European Spine Journal 17: 794-819

World Health Organization 2001 International Classification of Functioning Disability and Health. Geneva, World Health Organization 
Copyright of Physiotherapy Theory \& Practice is the property of Taylor \& Francis Ltd and its content may not be copied or emailed to multiple sites or posted to a listserv without the copyright holder's express written permission. However, users may print, download, or email articles for individual use. 